\title{
Concentration Fluctuation in Long Wavelength Limit in Liquid Magnesium Alloy
}

\author{
D. Adhikari*, B.P. Singh* , I.S. Jha** \\ *Univ. Dept. of Physics, T.M.Bhag. University, Bhagalpur, Bihar, India \\ ${ }^{* *}$ Dept. of Physics, M.M.A.M. Campus (Tribhuvan University), Biratnagar, Nepal \\ adksbdev@yahoo.com
}

\begin{abstract}
The microscopic structure of MgSn liquid alloy at 1073K has been studied by using regular associated solution model. For this we have calculated the concentration fluctuation in long wave length limit $\left[S_{C C}(0)\right]$ and chemical short range order parameter $\left(\alpha_{1}\right)$ of liquid MgSn alloy at $1073 \mathrm{~K}$.
\end{abstract}

Keywords: Binary Alloy; Complex; Chemical order, Microscopic Function

\section{Introduction}

Liquid alloys, which are disordered systems in the sense of having no long-range atomic or magnetic order, display a remarkable variety of local chemical order. Determination of short range order for alloys has been the subjects of active research for many years. Concentration fluctuation in long wave length limit $\left[\mathrm{S}_{\mathrm{CC}}(0)\right]$ and chemical short range order parameter $\left(\alpha_{1}\right)$ have emerged as powerful microscopic functions [1-8 ] to visualize the nature of chemical order in the alloy. The phenomena of segregation and compound formation are interpreted through the study of $\mathrm{S}_{\mathrm{CC}}(0)$ and $\alpha_{1}$

In this paper, we have determined the concentration fluctuation in long wave length limit $\left[\mathrm{S}_{\mathrm{CC}}(0)\right]$ and chemical short range order parameter $\left(\alpha_{1}\right)$ of liquid $\mathrm{MgSn}$ alloy at $1073 \mathrm{~K}$ using regular associated solution model. In regular associated solution model, it is assumed that strong associations among the constituent species exist in the liquid phase close to the melting temperature. These associations are given different names such as 'complexes', 'pseudomolecules', 'clusters', 'associations' etc. This assumption has been used by several researchers [9-17] to explain the asymmetry of the properties of mixing for binary alloys.

\section{Theory}

Let the binary alloy AB (=MgSn) consists of $n_{1}$ atoms of species A and $\mathrm{n}_{2}$ atoms of species B. Following Lele and Ramchandrarao [18], it is assumed that chemical complexes $A p B\left(A_{p} B<=>A p+B\right)$ exist in the melt, where $p$ is small integer which is usually determined from the compound - forming concentration $(=\mathrm{p} /(\mathrm{p}+1))$ in the solid state. Because of the existence of the compound, liquid alloys are supposed to be composed of three species, namely, monomers $\mathrm{A}(=\mathrm{Mg}), \mathrm{B}(=\mathrm{Sn})$ and complex $\mathrm{ApB}\left(=\mathrm{Mg}_{2} \mathrm{Sn}\right)$ in equilibrium. Let the concentration of $A, B$ and $A p B$ species be $n_{A}, n_{B}$, and $\mathrm{n}_{\mathrm{ApB}}$ moles respectively. In the partially associated solution the formation of $\mathrm{n}_{\mathrm{ApB}}$ complex requires $\mathrm{n}_{1}=\mathrm{n}_{\mathrm{A}}+\mathrm{p}$ ApB and $\mathrm{n}_{2}=\mathrm{n}_{\mathrm{B}}+\mathrm{n}_{\mathrm{ApB}}$ for conservation of mass. When there is association, the thermodynamic behaviour of complexes $\mathrm{A}$ and $\mathrm{B}$ components is governed by their true mole fractions $\mathrm{x}_{\mathrm{A}}, \mathrm{x}_{\mathrm{B}}$ and $\mathrm{x}_{\mathrm{ApB}}\left(\right.$ where $\mathrm{x}_{\mathrm{A}}=\frac{\mathrm{n}_{\mathrm{A}}}{\mathrm{n}_{\mathrm{A}}+\mathrm{n}_{\mathrm{B}}+\mathrm{n}_{\mathrm{ApB}}}$ etc.) rather than their gross mole fraction $\mathrm{x}_{1}$ and $\mathrm{x}_{2}$, (where $\mathrm{x}_{1}=\frac{\mathrm{n}_{1}}{\mathrm{n}_{1}+\mathrm{n}_{2}}$ etc.).

Following Lele and Ramchandrarao [18] for the reaction $A_{p} B \Leftrightarrow p A+B$ the equilibrium constant $(k)$ and the integral excess free energy of mixing ( $\Delta \mathrm{G}^{\mathrm{xs}}$ ) are given by

$\ln k=\ln \left(\frac{x_{A}^{p} x_{B}}{x_{A B B}}\right)+\frac{\omega_{12}}{R T}\left[p x_{B}\left(1-x_{B}\right)+x_{A}\right]+\frac{\omega_{1 B}}{R T}\left[p x_{A B B}\left(1-x_{A}\right)-x_{A}\right]+\frac{\omega_{23}}{R T}\left[x_{A B B}\left(1-p x_{B}\right)-x_{B}\right]$

and

$$
\begin{aligned}
\Delta G^{\times B}= & \frac{1}{\left(1+p x_{A B B}\right)}\left(x_{A} x_{B} \omega_{12}+x_{A} x_{A B B} \omega_{13}+x_{B} x_{A B B}\left(\omega_{23}\right)+\frac{R T}{\left(1+p x_{A B B}\right)} \times\right. \\
& \left(x_{A} \ln x_{A}+x_{B} \ln x_{B}+x_{A B B} \ln x_{A B B}\right)-R T\left(x_{1} \ln x_{1}+x_{2} \ln x_{2}\right)+\frac{x_{A B B}}{\left(1+p x_{A B B}\right)} R T \ln k
\end{aligned}
$$$$
\text { ............ (2) }
$$

Once the expressions for $\Delta \mathrm{G}\left[=\Delta \mathrm{G}^{\times 5}+\mathrm{RT}\left(\mathrm{x}_{1} \ln \mathrm{x}_{1}+\mathrm{x}_{2} \ln \mathrm{x}_{2}\right)\right]$ is obtained, the concentration fluctuations in the long-wavelength 
limit $(\mathrm{S} \neg \mathrm{cc}(0))$ is related to through standard thermodynamic relations

$$
\mathrm{S}_{\mathrm{CC}}(0)=\mathrm{RT}\left(\partial^{2} \Delta \mathrm{G} / \partial \mathrm{C}^{2}\right)_{\mathrm{T}, \mathrm{P}}^{-1}
$$

where $\mathrm{C}(=)$ is concentration of A component in the alloy Following D. Adhikari et al. [4], the $(\mathrm{S} \neg \mathrm{cc}(0))$ is given by

$$
S_{C C}(0)=\left\{\frac { 1 } { ( 1 + p x _ { A B B } ) } \left[\frac{2}{R T}\left(x_{A}^{\prime} x_{B}^{\prime} w_{12}+x_{A}^{\prime} x_{A B}^{\prime}\left(w_{13}+x_{B}^{\prime} x_{A B B}^{\prime}\left(w_{23}\right)+\left(\frac{x_{A}^{\prime 2}}{x_{A}}+\frac{x_{B}^{12}}{x_{B}}+\frac{x_{A B B}^{\prime 2}}{x_{A B B}}\right)\right]\right\}^{-1}\right.\right.
$$

where prime denotes the differentiations with respect to concentration and and are determined by using relations $\mathrm{x}_{\mathrm{A}}=\mathrm{x}_{1}-\mathrm{px}_{2} \mathrm{x}_{\mathrm{APB}}, \quad \mathrm{x}_{\mathrm{B}}=\mathrm{x}_{2}-\left(1-\mathrm{px}_{2}\right) \mathrm{x}_{\mathrm{APB}}, \mathrm{x}_{\mathrm{APB}}^{\prime}$ is determined using Equation (1) and the condition $\frac{d \ln k}{d C}=0$.

Experimental values of $\mathrm{SCC}(0)$ are directly calculated from the activity data [19] using the following Eqs. [20]:

$$
\begin{aligned}
\mathrm{S}_{\mathrm{CC}}(0) & =(1-\mathrm{C}) \mathrm{a}_{1}\left(\partial \mathrm{a}_{1} / \partial \mathrm{C}\right)_{\mathrm{T}, \mathrm{P}}^{-1} \\
= & C \mathrm{a}_{2}\left(\partial \mathrm{a}_{2} / \partial(1-\mathrm{C})\right)_{\mathrm{T}, \mathrm{P}}^{-1}
\end{aligned}
$$

where $\mathrm{a}_{1}$ and $\mathrm{a}_{2}$ are the activities of $\mathrm{Mg}$ and $\mathrm{Sn}$ components respectively.

The chemical short range order parameter $\left(\alpha_{1}\right)$ can be determined from the knowledge of $\mathrm{S}_{\mathrm{CC}}\left(0[2,21]\right.$. The ${ }_{1}$ is given by

$$
\alpha_{1}=\frac{S-1}{S(Z-1)+1}, \quad S=\frac{S_{c c}(0)}{S_{c c}^{\text {id }}(0)}
$$

where $\mathrm{Z}$ is coordination number and its value is taken 10 for our calculation. We note that varying the value of $\mathrm{Z}$ does not have any effect on the position of the minima of $a_{1}$; the effect is to vary the depth while the overall feature remains unchanged.

\section{Results and Discussion}

We used Eq. (4) to calculate the concentration fluctuation in long wavelength limit $\operatorname{Scc}(0)$. For this we need mole fraction of the complex $\left(\mathbf{X}_{\mathrm{Mg}_{2} \mathrm{Sn}}\right)$ and pairwise interaction energies parameters ( $\left.\omega_{i j}\right)$. These parameters were taken from the reference [18]. Figure 1 shows the computed and experimental values of $\operatorname{Scc}(0)$ as well as ideal values. The calculated values for $\operatorname{Scc}(0)$ shows reasonable agreement with the experimental values. $\operatorname{Scc}(0)$ can be used to understand the nature of atomic order in the binary liquid alloys $[22,23]$.

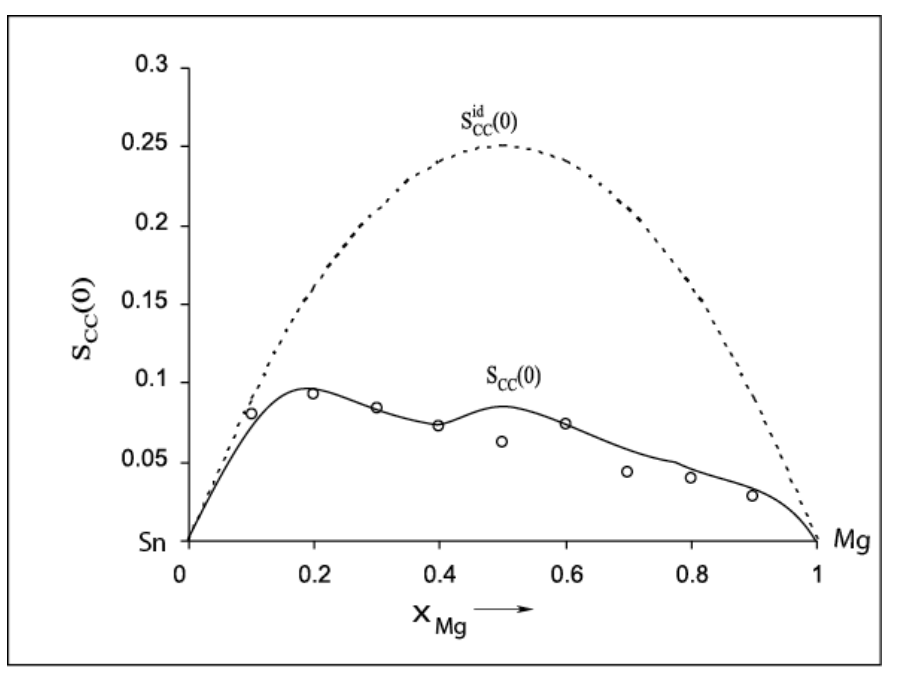

Fig. 1 : Concentration fluctuations in long wavelength limit $\left(S_{c c}(0)\right)$ versus $x_{M g}$ of liquid MgSn solution (1073K); (-) theory, (०००) experiment, (----) ideal values.

The condition for occurring order in liquid alloy is $\operatorname{Scc}(0)<S_{c c}^{\text {id }}(0)$ , and if $\operatorname{Scc}(0)>S_{c c}^{\text {id }}(0)$, there is tendency of segregation. Our theoretical analysis shows that the order exists for MgSn alloy in the liquid state at whole concentration range. We have found that the deviation of $\operatorname{Scc}(0)$ from the ideal value is maximum $(=0.168)$ at $\mathbf{X}_{\mathrm{Mg}}=0.61$

The knowledge of $\alpha_{1}$ provides an immediate insight into the nature of the local arrangements of atoms in the mixture. At equiatomic composition, one has $-1 \leq \alpha_{1} \leq 1$. The minimum possible value of $a_{1}$ is -1 and that implies complete ordering of unlike atoms paring at nearest neighbours. On the other hand the maximum value of $a_{1}$ is +1 which implies total segregation leading to the phase separation and $\alpha_{1}=0$ corresponds to a random distribution of atoms. Figure 2 shows that $\alpha_{1}$ are negative throughout, showing MgSn is ordering system of unlike atoms paring at all compositions. The asymmetry in $\alpha_{1}$ is distinctly noticeable. 


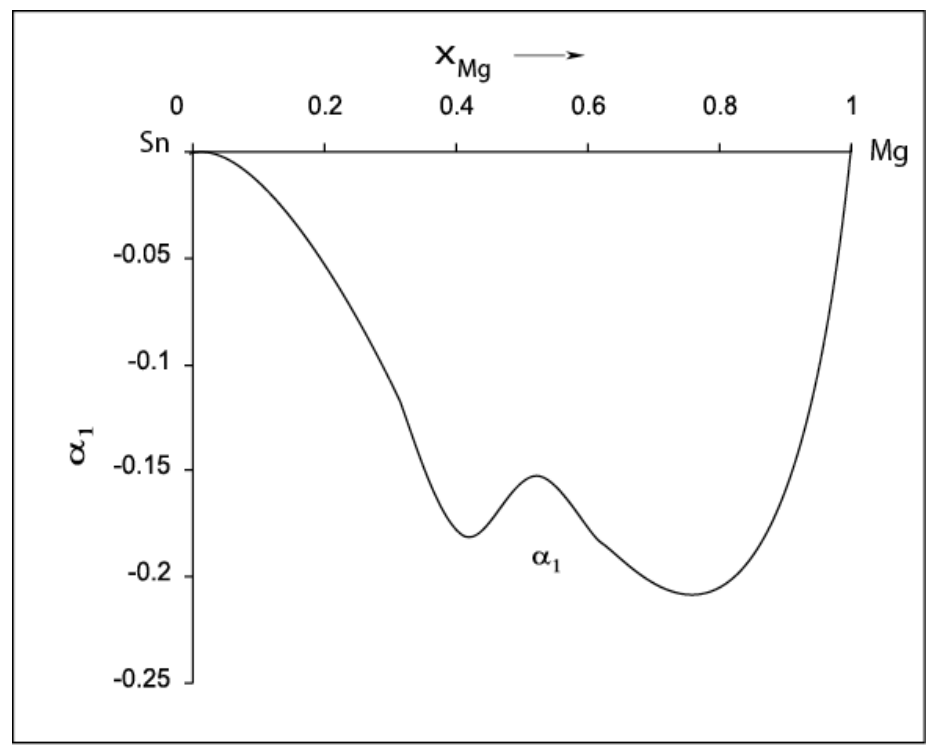

Fig. 2 : Short range ordering parameter $\left(\alpha_{1}\right)$ of liquid MgSn solution (1073K) versus $x_{M g}$.

\section{Conclusion}

Computed results of concentration-fluctuation in long wavelength limit and chemical short range order parameter suggest that there is a tendency of unlike atoms pairing (Mg-Sn) in MgSn alloys at all concentration.

\section{Acknowledgement}

D. Adhikari gratefully acknowledges the support of the University Grant Commission (UGC) of Nepal.

\section{References}

[1] R.N. Singh, Can J. Phys. 65 (1987) 309.

[2] A.B. Bhatia and R.N. Singh, Phys. Chem. Liquid 13(1984) 177.

[3] B.P. Singh , D. Adhikari and I.S. Jha, J. Non-Crystalline Solids 356 (2010) 1730.

[4] D. Adhikari, I.S. Jha and B.P. Singh, Phil. Mag. 90(2010) 2687.

[5] A.B. Bhatia and W.H. Hargrove, Phys. Rev. 10 (1974)3186.

[6] K. S. Attri;,P. K. Ahluwalia and K. C. Sharma, Phys. Chem. Liqs. 26(1994) 225.

[7] Th. Proffen,,V. Petkov,, S. J. L. Billinge and T. Vogt, Z. Kristallogr 217 (2002) 47.
[8] L. C. Prasad and V. N. Singh, Z. Naturforsch 55a (2000) 967.

[9] S.P. McAlister and E.D. Crozier, J. of Phys. C7(1974) 3509.

[10] U. Gerling, M. J. Pool and B. Predel, Z. Metallkde 74(1983) 616.

[11] K. Hoshino and W.H. Young, J. of Phys. F: Met. Phys. 10(1980) 1365.

[12] A.S. Jordan, Metall. Trans. 1 (1970) 239.

[13] K. Osmura and B. Predel , Tans. J. Phys. Inst. Met. 18 (1977) 765.

[14] A.B. Bhatia and R. N. Singh, Phys. Letters A78(1980) 460.

[15] A.B. Bhatia and N.H. March, Phys. Letters A 51(1975) 401.

[16] N.Jha and A.K. Mishra, J. Alloys and compounds 329(2001) 224.

[17] B.C .Anusionwu, J. Alloys and compounds, 359(2003) 172.

[18] S. Lele and P. Ramchandra Rao, Metall. Trans. 12 B (1981) 659.

[19] R. Hultgren, P. D. Desai, D.T. Hawkins, M. Gleiser a nd K. K. Kelly, Selected values of the Thermodynamic Properties of Binary Alloys (ASM,Metal Park)1973.

[20] T.S. Yih and J.C. Thompson, J. Phys.F. Met. Phys. 12 (1982) 1625.

[21] N.K.P. Singh, R.N. Singh and R.B. Choudhary, J. Phys. Condens. Matter 3(1991) 5345.

[22] R.N. Singh, I.K. Mishra and V.K. Slngh,J. Phys.: Condens. Matter 2(1990) 8445.

[23] L.C. Prasad and R.N. Singh , Phys. Chem. Liquid 22(1990) 1. 